\title{
Polysomnography shows sleep fragmentation in patients with inactive inflammatory bowel disease
}

\author{
Candace Beilman ${ }^{\mathrm{a}}$, Alexandra Dittrich ${ }^{\mathrm{a}}$, Holly Scott ${ }^{\mathrm{b}}$, Brian McNabc, Lily Olayinka ${ }^{\mathrm{a}}$, Karen I. Kroeker ${ }^{\mathrm{a}}$ \\ University of Alberta, Edmonton, AB; Alberta Health Services, Edmonton, AB, Canada
}

\section{Abstract}

\section{Introduction}

Inflammatory bowel disease (IBD), including Crohn's disease (CD) and ulcerative colitis (UC), is a chronic, remitting

${ }^{a}$ Division of Gastroenterology, Department of Medicine, Centre of Excellence for Gastrointestinal Inflammation and Immunity Research, (Candace Beilman, Alexandra Dittrich, Lily Olayinka, Karen I. Kroeker); b Alberta Health Services, Edmonton, AB, Canada (Holly

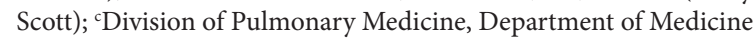
(Brian McNab), University of Alberta, Edmonton, AB, Canada

Conflicts of Interest: None

Correspondence to: Karen I. Kroeker, 2-40 Zeidler Ledcor Centre, University of Alberta, Edmonton, AB T6G 2X8, Canada, e-mail: karen. kroeker@ualberta.ca

Conference Presentation: This study was presented as a poster at Digestive Diseases Week 2017, Chicago, IL, USA

Received 20 May 2020; accepted 29 June 2020; published online 16 September 2020

DOI: https://doi.org/10.20524/aog.2020.0529 and relapsing condition characterized by inflammation of the gastrointestinal tract. While the predominant symptoms of IBD include diarrhea, nocturnal bowel movements, rectal bleeding and abdominal pain, fatigue is a common complaint [1]. Even when the gastrointestinal symptoms are in complete remission, fatigue can remain a dominant symptom and can have a dramatically negative impact on the quality of life for many patients [2].

Recently, we examined the prevalence of fatigue in our population of IBD patients attending the University of Alberta IBD Consultation and Research Clinic in 2013. We evaluated fatigue in 322 patients using the validated Functional Assessment of Chronic Illness Therapy-Fatigue (FACIT-F) [3] measurement tool and identified that $53.7 \%$ of patients with IBD had severe fatigue. Similarly, several studies have found higher prevalence rates of fatigue in the IBD population compared with the general population [2,4-6]. Although the prevalence of fatigue is well-established in this patient population, the cause of the fatigue in IBD patients in remission is currently not well understood.

It has been suggested that sleep quality may be a factor contributing to the fatigue experienced by these patients. Sleep 
plays a vital role in maintaining mental and physical health, and is critical in regulating inflammation and the immune system [7]. Many studies have demonstrated that patients with IBD self-report sleep disturbances, which may contribute to disease flares and affect disease management [8]. However, although disturbances in sleep and fatigue may be aggravated by disease activity, they have been shown to be significant even when the disease is in full remission [9]. Indeed previous reports have confirmed that $50 \%$ of patients with IBD in remission complain of poor sleep quality [10].

In a typical night, there are 2 types of sleep: rapid-eyemovement (REM) and non-REM (NREM) sleep. In total, there are 4 scored sleep stages, N1, N2, N3 and REM, each corresponding to specific brain waves and neural activity [11]. Generally, people follow a predictable sleep cycle by transitioning through the various sleep stages approximately every $90 \mathrm{~min}$. N1 and N2 are considered to be relatively light stages of sleep, whereas $\mathrm{N} 3$ is characterized by slow waves that result in deep and restorative sleep, where the sleeper is less responsive to the outside environment. People on average spend $5 \%, 45 \%, 25 \%$, and $25 \%$ in sleep stages N1, N2, N3, and REM, respectively [12]. However, there are normal age-related changes in sleep architecture, including an increase of N1 and $\mathrm{N} 2$ sleep and a decrease of N3 sleep in older adults [13]. Often, altered sleep stages can contribute to increased levels of fatigue, even if a full night of sleep is experienced [14].

The aim of our study was to assess sleep quality in patients with inactive IBD who reported fatigue. We conducted a pilot study to objectively assess sleep patterns and disturbances using gold-standard criteria, as well as assessing their associations with subjective markers of fatigue, sleep quality and the prevalence of depression in patients with IBD.

\section{Patients and methods}

\section{Study design}

We conducted a prospective observational pilot study to examine sleep quality in outpatients with IBD (CD or UC). Patients were recruited from April 2016 to February 2017 at the University of Alberta IBD Consultation and Research Clinic, Edmonton, Alberta, Canada. The study was approved by the Research Ethics Board at the University of Alberta, and consent to participate in the study was obtained from all subjects.

After signing consent forms, eligible patients were asked to complete a demographic questionnaire including age, sex, type and distribution of disease, age of diagnosis, and medication information. They were also asked to complete 3 validated questionnaires that assess subjective fatigue levels, sleep quality and depression levels: 1) Functional Assessment of Chronic Illness Therapy - Fatigue (FACIT-F), a 13-item patientadministered questionnaire with a range of $0-52$, where lower scores indicate worse fatigue [15]; 2) Pittsburgh Sleep Quality Index (PSQI), a self-reported questionnaire with 7 component scores added to yield one global score with a range of $0-21$, where higher scores indicate worse sleep quality [16]; and 3) Beck
Depression Inventory-II (BDI-II), a widely used psychometric test for measuring the severity of depression using 21 multiplechoice questions, each being scored from 0-3, with higher total scores indicating more severe depression [17].

Upon completing the questionnaire, patients were studied with Level 1 diagnostic polysomnography (PSG) at the University of Alberta Sleep Disorders Laboratory. PSG was conducted following the 2017 American Academy of Sleep Medicine protocol with a registered PSG technologist (RPSGT) in attendance. Patients were connected to an electroencephalogram (EEG), electromyogram, electrocardiogram to monitor brain activity, muscle tension and movement, and electrical activity of the heart, respectively. Furthermore, Respitrace bands were used on the abdomen and chest to monitor chest and abdominal effort. Nasal and oral airflow were measured to determine the rate of respiration and the respiratory effort, and to identify any interruptions in breathing. Lastly, pulse oximetry measured blood oxygen levels and snoring was recorded with a sound probe located on the neck. A registered sleep technologist with extensive experience performed PSG scoring, and a physician with expertise in sleep disorders reviewed sleep studies.

\section{Patient population}

Patients were eligible for inclusion if they met the following criteria: 1) confirmed diagnosis of either CD or UC; 2) in remission, determined by a Harvey-Bradshaw Index $<5$ or a Partial Mayo Score of 0 or 1 , and a fecal calprotectin level $<250$ $\mathrm{mg} / \mathrm{kg}$; and 3) subjective complaints of fatigue. Patients were excluded from the study if they had active disease, had other chronic illness apart from IBD, worked night shifts, had a body mass index (BMI) of 35 or higher, used sleep medications and/ or narcotics, had iron deficiency, or if they or their partner had a baby or had adopted a baby within the last year. A total of 15 IBD outpatients were included in the study (7 with CD and 8 with UC).

\section{Outcomes}

In order to objectively assess sleep quality, the primary objective of our study was to measure sleep fragmentation using PSG in patients with inactive IBD who experienced fatigue. The outcomes used to assess sleep fragmentation included spontaneous EEG arousals and percent of sleep time in each sleep stage. Secondary objective outcomes included measures of sleep architecture, respiratory events, and periodic limb movements of sleep (PLMS). Secondary subjective outcomes included FACIT-F, PSQI, and BDI-II questionnaire scores.

\section{Statistical analysis}

For parameters with a normal distribution, mean and standard deviation were used as descriptive statistics. For 
parameters without a normal distribution, median and interquartile range (IQR) were used as descriptive statistics. Non-parametric methods were used for group comparisons because of our small sample size. Correlation analysis was performed to determine any relations between variables. A $\mathrm{P}$-value $<0.05$ was used as the level of statistical significance. Statistical analysis was performed using SPSS 24.0 statistical software (Armonk, NY: IBM Corporation).

\section{Results}

Demographic data are reported in Table 1. The mean age of the participants was $35.5 \pm 10.3$ years. Seven patients $(46.7 \%)$ had CD and $8(53.3 \%)$ had UC. Eleven (73.3\%) patients were female. The mean BMI for our patient population was $25.8 \pm 5.7 \mathrm{~kg} / \mathrm{m}^{2}$. Mean fecal calprotectin value was $109.5 \pm 91.6$ $\mathrm{mg} / \mathrm{g}$. Patients were taking the following medications: biologics (53.3\%), azathioprine (33.3\%), and mesalamine (26.7\%). There were no statistical differences between $\mathrm{CD}$ and UC patients apart from sleep latency, which was longer in $\mathrm{CD}$ patients compared to UC patients $(\mathrm{P}<0.001)$.

\section{Questionnaires}

Participants had an average score of $30.1 \pm 10.4$ on the FACIT-F questionnaire, an average PSQI score of $7.9 \pm 3.6$, and an average BDI-II score of $12.8 \pm 9.8$.

\section{Sleep architecture}

Participants slept a median of $384.0(\mathrm{IQR}=60.2) \mathrm{min}$ and had a median sleep efficiency of $85.8 \%$ (IQR=5.8). Mean sleep-onset latency (the time to transition from wakefulness to sleep) was $16.9 \pm 12.3 \mathrm{~min}$. Sleep latency was significantly higher in CD patients compared to UC patients (28.0 vs. 8.6 min, $\mathrm{P}=0.001)$. The median latency to rapid eye movement (REM) sleep was $81.5(\mathrm{IQR}=135.3) \mathrm{min}$. Sleep-onset latency

Table 1 Demographic characteristics of participants

\begin{tabular}{lc}
\hline Characteristics & Participants $(\mathrm{n}=15)$ \\
\hline Disease type $(\% \mathrm{CD})$ & $46.7 \%$ \\
Sex $(\%$ Female) & $73.3 \%$ \\
Age (years $\pm \mathrm{SD})$ & $35.3 \pm 10.3$ \\
Fecal calprotectin $(\mathrm{mg} / \mathrm{g} \pm \mathrm{SD})$ & $109.5 \pm 91.6$ \\
Body mass index $\left(\mathrm{kg} / \mathrm{m}^{2} \pm \mathrm{SD}\right)$ & $25.8 \pm 5.7$ \\
Medications $(\%)$ & \\
Biologics & $53.3 \%$ \\
Azathioprine & $33.3 \%$ \\
Mesalamine & $26.7 \%$ \\
\hline
\end{tabular}

$C D$, Crohn's disease; $S D$, standard deviation was inversely related to age $(r=-0.65, P=0.01)$. Finally, BMI inversely correlated with sleep latency $(\mathrm{r}=-0.61, \mathrm{P}=0.02)$.

\section{Sleep stages}

Patients spent an average of $6.6 \pm 3.9 \%, 60.4 \pm 8.2 \%$ and $15.2 \pm 9.8 \%$ of their total sleep time in stages N1, N2 and N3, respectively. REM sleep encompassed $17.9 \pm 5.3 \%$ of their total sleep time.

Age positively correlated with percentage of N2 sleep $(\mathrm{r}=0.70, \mathrm{P}=0.006)$ and inversely related to percentage of $\mathrm{N} 3$ sleep $(r=-0.72, P=0.004)$, results consistent with the normal age-related changes in sleep architecture. The spontaneous EEG arousal index (number of EEG arousals $/ \mathrm{h} / \mathrm{h}$ ) positively correlated with percentage of $\mathrm{N} 1$ sleep $(\mathrm{r}=0.71, \mathrm{P}=0.005)$. Finally, FACIT-F scores were inversely related to percentage of N1 sleep $(r=-0.54, P=0.05)$.

\section{Medications and sleep stages}

Patients on azathioprine had a significantly lower percentage of $\mathrm{N} 2$ sleep ( $53.6 \%$ vs. $64.1 \%, \mathrm{P}=0.01$ ), and a higher percentage of $\mathrm{N} 3$ sleep $(22.6 \%$ vs. $11.1 \%, \mathrm{P}=0.02)$ compared to those not on azathioprine. Patients on mesalamine had a lower percentage of $\mathrm{N} 1$ (3.2\% vs. $7.9 \%, \mathrm{P}=0.02)$ and a higher percentage of $\mathrm{N} 2$ sleep $(67.8 \%$ vs. $57.4 \%, \mathrm{P}=0.04)$ compared to those not on mesalamine.

\section{Arousals}

Patients had a mean spontaneous EEG arousal index of

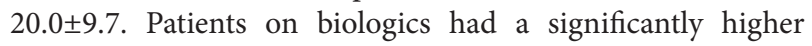
spontaneous EEG arousal index compared to patients not on biologics ( 23.0 vs. $16.0, \mathrm{P}=0.04$ ). REM latency positively correlated with spontaneous EEG arousal index $(\mathrm{r}=0.54$, $\mathrm{P}=0.04)$.

\section{Respiratory events}

The apnea-hypopnea index (AHI), the number of apnea and hypopnea events per hour of sleep, was $>5 / \mathrm{h}$ for 4 (26.7\%) patients. Three $(20.0 \%)$ patients fell in the mild obstructive sleep apnea range $(\mathrm{AHI}=5-15 / \mathrm{h})$, and one $(6.7 \%)$ patient had severe obstructive sleep apnea $(\mathrm{AHI} \geq 30 / \mathrm{h})$. BMI positively correlated with AHI $(r=0.60, P=0.02)$, as well as with the Oxygen Desaturation Events Index $(r=0.65, \mathrm{P}=0.01)$.

\section{PLMS}

PLMS were experienced in 7 (46.7\%) patients: mild PLMS in $6(40.0 \%)$ patients, and moderate PLMS in one (6.7\%). However, no patients experienced PLMS associated with a 
spontaneous EEG arousal of index of greater than $15 / \mathrm{h}$. Mean values of objective sleep parameters are reported in Table 2. Individual patient data are reported in Table 3.

\section{Discussion}

This pilot study examined subjective and objective markers of sleep in patients with inactive IBD to identify altered sleeping patterns and sleep disturbances that contribute to the fatigue experienced by this patient population. We found that our patient population had a greater level of perceived fatigue and worse subjective sleep quality compared to previously published scores of healthy controls. We determined that IBD patients had altered sleeping patterns based on sleep architecture and abnormal sleep stages. In addition, we found that IBD patients had high rates of respiratory events, arousals and PLMS that contributed to fragmented sleep.

One previous study used PSG to measure sleep quality in patients with inactive IBD [9]. Sixteen IBD patients were included in the study, as well as 9 patients with irritable bowel syndrome (IBS) and 7 healthy controls. The study found no significant differences between the IBD and IBS groups in any objective sleep parameters, and the only significant differences seen were a shorter total sleep time and less sleep efficiency in IBS patients compared to controls. No significant differences were seen between IBD patients and controls; however, there were numerical trends indicating higher values of N1 sleep percentage, arousal index, apneahypopnea index and PLMS in IBD patients. The strengths of this study were that it included control groups, and that it compared objective and subjective markers of sleep quality. However, this study did not look at the relationship between objective sleep parameters and other confounding factors, such as age, sex, BMI, medication use, or objective markers of disease activity, such as blood and stool markers, important for determining the factors related to the patient's poor sleep quality.

In order to compare our subjective outcomes of IBD patients to those of healthy adults, we obtained data from previously published literature. We found that patients with IBD had lower FACIT-F questionnaire scores (30.4 vs. 43.6) compared to healthy adults, indicating higher levels of subjective fatigue [18]. In addition, we found that our patients with IBD had higher PSQI questionnaire scores (7.6 vs. 3.2) compared to healthy adults, indicating lower perceived sleep quality [19]. Lastly, it appeared that our IBD sample had slightly higher scores on the BDI-II questionnaire (12.7 vs. 7.8), indicating higher levels of depression compared to healthy adults [20]. Marinelli et al showed that depressed patients were also more affected by sleep disturbance (measured by the PSQI questionnaire), while no difference in sleep disturbance was found for patients with or without anxiety [21]. Furthermore, this study showed that poor sleep was not correlated with disease activity, but was correlated with quality of life and mood states. This suggests that an improvement in sleep and mood is an important treatment consideration for these patients to improve their overall quality of life.

Although our study did not include a control group, because of limited sleep lab availability and budget constraints, previously published data were available for 470 healthy adults who underwent PSG with similar exclusion criteria to our study, who could therefore act as an appropriate control group [22]. Based on our PSG results, we determined that patients with IBD spent a greater percentage of total sleep time in N2 sleep (60.4\% vs. $54.3 \%)$ and a shorter percentage in N3 ( $15.2 \%$ vs. $20.4 \%$ ) compared to healthy controls. This may be

Table 2 Objective sleep parameters by disease type

\begin{tabular}{|c|c|c|c|c|}
\hline Sleep Parameter & $\operatorname{IBD}(n=15)$ & $\mathrm{CD}(\mathrm{n}=7)$ & $\mathrm{UC}(\mathrm{n}=8)$ & P-value ${ }^{*}$ \\
\hline Total sleep time ${ }^{\mathrm{a}}$, min & $384.0(60.2)$ & $382.5(79.3)$ & $401.8(47.1)$ & 0.345 \\
\hline Sleep efficiency ${ }^{\mathrm{a}}, \%$ & $85.8(5.8)$ & $84.0(15.0)$ & $87.6(4.7)$ & 0.181 \\
\hline Sleep latency, min & $16.9(12.3)$ & $29.6(8.4)$ & $8.6(3.8)$ & 0.001 \\
\hline N1 sleep, \% & $6.6(3.9)$ & $7.9(3.4)$ & $5.4(4.1)$ & 0.142 \\
\hline N2 sleep, \% & $60.4(8.2)$ & $58.3(7.9)$ & $63.0(8.4)$ & 0.282 \\
\hline N3 sleep, \% & $15.2(9.8)$ & $17.2(8.6)$ & $12.1(10.7)$ & 0.282 \\
\hline REM sleep, \% & $17.9(5.3)$ & $16.6(5.7)$ & $19.5(4.9)$ & 0.228 \\
\hline REM sleep latency ${ }^{\mathrm{a}}$, min & $81.5(135.3)$ & $173.4(106.2)$ & $75.8(47.0)$ & 0.181 \\
\hline Spontaneous EEG arousal index, \#/h & $20.0(9.7)$ & $24.8(12.7)$ & $19.3(5.8)$ & 0.662 \\
\hline Apnea/hypopnea index ${ }^{\mathrm{a}}$ \# /h & $0.6(3.7)$ & $0.3(6.6)$ & $1.3(3.0)$ & 0.573 \\
\hline Oxygen desaturation events index ${ }^{\mathrm{a}}, \# / \mathrm{h}$ & $2.6(7.5)$ & $2.6(3.5)$ & $3.3(10.7)$ & 0.755 \\
\hline Periodic leg movement index ${ }^{\mathrm{a}}, \# / \mathrm{h}$ & $0.0(8.8)$ & $0.0(6.0)$ & $2.2(11.4)$ & 0.282 \\
\hline
\end{tabular}

${ }^{\star} \mathrm{P}$-value comparing UC and CD patients

Data are presented as mean \pm SD for continuous variables. Median $\pm \mathrm{IQR}$ is reported for non-continuous variables and denoted by ${ }^{\mathrm{a}}$

$I B D$, inflammatory bowel disease; CD, Crohn's disease; UC, ulcerative colitis; REM, rapid eye movement; EEG, electroencephalography; SD, standard deviation 
Table 3 Individual patient data showing demography and scores from questionnaires and polysomnography

\begin{tabular}{|c|c|c|c|c|c|c|c|c|c|}
\hline Patient & Sex & Age & $\begin{array}{l}\text { Disease } \\
\text { type }\end{array}$ & BMI & FACIT-F* & $\begin{array}{l}\text { Pittsburgh } \\
\text { sleep } \\
\text { quality } \\
\text { index }\end{array}$ & $\begin{array}{l}\text { Beck's } \\
\text { depression } \\
\text { inventory } \\
\text { score }\end{array}$ & $\begin{array}{l}\text { Normal }(\mathrm{N}) \\
\text { or abnormal } \\
\text { (A) sleep }\end{array}$ & Abnormalities \\
\hline 1 & $\mathrm{~F}$ & 35 & UC & 28.2 & $\begin{array}{l}\text { Non- } \\
\text { severe } \\
(39)\end{array}$ & 3 & Minimal & $\mathrm{N}$ & \\
\hline 2 & $\mathrm{~F}$ & 34 & UC & 33.5 & $\begin{array}{l}\text { Non- } \\
\text { severe } \\
(47)\end{array}$ & 4 & Minimal & $\mathrm{N}$ & \\
\hline 3 & $\mathrm{~F}$ & 31 & $\mathrm{CD}$ & 21.8 & $\begin{array}{l}\text { Severe } \\
(29)\end{array}$ & 7 & Minimal & $\mathrm{N}$ & \\
\hline 4 & $\mathrm{~F}$ & 41 & UC & 18.2 & $\begin{array}{l}\text { Non- } \\
\text { Severe } \\
(41)\end{array}$ & 2 & Minimal & A & Low $\%$ of $\mathrm{N} 3$ sleep \\
\hline 5 & M & 52 & UC & 29.4 & $\begin{array}{l}\text { Severe } \\
(20)\end{array}$ & 11 & Mild & A & $\begin{array}{l}\text { Low \% of N3 sleep; High \% of } \\
\text { N2 sleep }\end{array}$ \\
\hline 6 & M & 29 & $\mathrm{CD}$ & 22.5 & $\begin{array}{l}\text { Non- } \\
\text { severe } \\
(47)\end{array}$ & 5 & Minimal & A & $\begin{array}{l}\text { Low sleep efficiency; High sleep } \\
\text { latency }\end{array}$ \\
\hline 7 & $\mathrm{~F}$ & 44 & UC & 29.2 & $\begin{array}{l}\text { Non- } \\
\text { severe } \\
(32)\end{array}$ & 10 & Minimal & A & $\begin{array}{l}\text { Low \% of } \mathrm{N} 3 \text { sleep; Mild periodic } \\
\text { limb movements of sleep }\end{array}$ \\
\hline 8 & $\mathrm{~F}$ & 21 & $\mathrm{CD}$ & 21.4 & $\begin{array}{l}\text { Non- } \\
\text { severe } \\
(31)\end{array}$ & 9 & Mild & A & $\begin{array}{l}\text { High sleep latency; High REM } \\
\text { latency; High arousal index; Mild } \\
\text { periodic limb movements of sleep }\end{array}$ \\
\hline 9 & $\mathrm{~F}$ & 32 & $\mathrm{CD}$ & 20.9 & $\begin{array}{l}\text { Severe } \\
(19)\end{array}$ & 5 & Minimal & A & $\begin{array}{l}\text { High REM latency; High arousal } \\
\text { index; High \% of N1 sleep; Low } \\
\% \text { of N3 sleep; Mild periodic limb } \\
\text { movements of sleep }\end{array}$ \\
\hline 10 & $\mathrm{~F}$ & 19 & $\mathrm{CD}$ & 17.9 & $\begin{array}{l}\text { Severe } \\
(13)\end{array}$ & 12 & Severe & A & $\begin{array}{l}\text { High REM latency; High \% of N1 } \\
\text { sleep; Low \% of REM sleep; Mild } \\
\text { periodic limb movements of sleep }\end{array}$ \\
\hline 11 & $\mathrm{~F}$ & 41 & UC & 24.6 & $\begin{array}{l}\text { Severe } \\
(20)\end{array}$ & 14 & Moderate & A & $\begin{array}{l}\text { High arousal index; High \% } \\
\text { of N1 sleep; Low \% of N3 } \\
\text { sleep; Moderate periodic limb } \\
\text { movements of sleep }\end{array}$ \\
\hline 12 & M & 33 & $\mathrm{CD}$ & 29.6 & $\begin{array}{l}\text { Non- } \\
\text { severe } \\
(37)\end{array}$ & 8 & Mild & A & $\begin{array}{l}\text { Low sleep efficiency; High REM } \\
\text { latency; High arousal index; Low } \\
\% \text { of REM sleep; Mild obstructive } \\
\text { sleep apnea }\end{array}$ \\
\hline 13 & $\mathrm{~F}$ & 30 & UC & 34.6 & $\begin{array}{l}\text { Severe } \\
(23)\end{array}$ & 7 & Minimal & A & $\begin{array}{l}\text { High arousal index; Mild periodic } \\
\text { limb movements of sleep; Mild } \\
\text { obstructive sleep apnea }\end{array}$ \\
\hline 14 & $\mathrm{~F}$ & 56 & UC & 33.6 & $\begin{array}{l}\text { Severe } \\
(27)\end{array}$ & 9 & Severe & A & $\begin{array}{l}\text { High arousal index; Low \% } \\
\text { N3 sleep; Mild periodic limb } \\
\text { movements of sleep; Mild } \\
\text { obstructive sleep apnea }\end{array}$ \\
\hline 15 & M & 36 & $\mathrm{CD}$ & 21.9 & $\begin{array}{l}\text { Severe } \\
(26)\end{array}$ & 12 & Mild & A & $\begin{array}{l}\text { High arousal index; Low \% N3 } \\
\text { sleep, Severe obstructive sleep } \\
\text { apnea }\end{array}$ \\
\hline
\end{tabular}

${ }^{*}$ Scores below 30 are considered to be severe fatigue

$M$, male; F, female; UC, ulcerative colitis; CD, Crohn's disease; REM, rapid eye movement; BMI, body mass index; FACIT-F, Functional Assessment of Chronic Illness Therapy-Fatigue 
problematic, because stage $\mathrm{N} 3$ has an important role in cerebral restoration, physical recovery and memory consolidation; therefore, a shortage of $\mathrm{N} 3$ sleep can lead to excessive daytime fatigue, even when a full night of sleep occurs [23]. Furthermore, our IBD patients had a lower percentage of REM sleep compared to healthy controls (17.9\% vs. $20.9 \%)$. This was congruent with the observation in a recent study [24]. Lastly, our IBD study sample had a mean spontaneous EEG arousal index higher than that of healthy controls (20.0 vs. 14.3), indicating a greater amount of sleep fragmentation in our study population. Our study found correlations between the percentage of $\mathrm{N} 1$ sleep, the number of spontaneous EEG arousals and the subjective fatigue experienced by a patient. Spontaneous EEG arousals are an important indicator of sleep quality used to assess sleep fragmentation, frequent interruptions and lack of continuity in sleep [25]. We found that our IBD patient population had a higher spontaneous EEG arousal index compared to the general population, and that an increase in arousal index correlated with an increased percentage of N1 sleep. We also found that patients with higher subjective fatigue also had a greater percentage of N1 sleep. An increased percentage of N1 sleep is generally an indicator of increased sleep fragmentation, which in turn leads to stronger subjective feelings of fatigue [26].

The association between spontaneous EEG arousal index, percentage of $\mathrm{N} 1$ sleep and subjective fatigue allows us to speculate that if a therapeutic intervention was able to decrease arousals and therefore N1 sleep, subjective fatigue might decrease in these patients. To decrease spontaneous EEG arousals, it is important to consider the cause of the arousal. For instance, sleep apnea is a common cause of frequent spontaneous EEG arousals with sleep fragmentation [27], which can be corrected using continuous positive airway pressure therapy to increase air pressure in a patient's airways, subsequently preventing airway obstruction during sleep [28]. PLMS are another common cause of increased spontaneous EEG arousals. The frequency of PLMS with associated arousals can be decreased using various pharmacologic therapies. First, if patients who experience PLMS have low ferritin levels, iron replacement is suggested. In addition, melatonin has been shown to significantly reduce PLMS and movement rates during time in bed as measured by actigraphy [29]. Lastly, benzodiazepines, dopaminergic agents, anticonvulsants and GABA agonists have been shown to relieve symptoms associated with PLMS [30].

This study had some limitations. As previously mentioned, it had a small sample size and lacked a control group because of budget constraints and sleep lab availability. In order to compare our results to healthy controls, we used previously published data from 470 healthy adults who underwent PSG as a control group. We were unable to control for potentially confounding variables, as we were unable to further split our already small sample size into smaller samples. Furthermore, our sample population was a convenience sample, as we recruited patients currently attending our clinic; this may have contributed to selection bias. Although an equal number of males and females were approached about the study, our study had a higher proportion of females compared to males. We hypothesize this may have been due to a higher incidence of fatigue in the female population, or to a greater willingness to participate in the study. Finally, although PSG is an objective test, interobserver variability may exist in the scoring of sleep stages. In order to reduce the amount of variation from one scorer to the next, we ensured that the same sleep technologist with extensive experience scored all of our studies.

Our study examined sleep quality using PSG in patients with IBD, while making important connections with patients' demographics, disease behavior, subjective questionnaire scores and medication use. This not only allowed us to determine whether patients experienced sleep disturbances, but also let us investigate which factors contributed to poor sleep quality. Overall, patients with IBD experienced altered sleep patterns in terms of the percentage of time spent in each sleep stage, as well as high rates of sleep fragmentation. Given the high rates of sleep disorders seen in our IBD patient sample, it may be useful for IBD patients who complain of fatigue to be evaluated for sleep disorders that may contribute to this fatigue. Further interventional research in a larger population is needed to determine the causes of poor sleep quality and how it can be treated in this patient population.

\section{Summary Box}

\section{What is already known:}

- Fatigue is a dominant symptom in patients with inflammatory bowel disease (IBD)

- IBD patients frequently self-report sleep disturbances

- Sleep disturbances and fatigue may be aggravated by disease activity

\section{What the new findings are:}

- IBD patients with inactive disease may have high rates of respiratory events, arousals, and periodic limb movements of sleep that contribute to fragmented sleep

- Shortage of deep sleep in IBD patients may result in excessive daytime fatigue

- IBD patients may have a lower percentage of rapideye-movement sleep compared to healthy controls

\section{References}

1. de Rooy EC, Toner BB, Maunder RG, et al. Concerns of patients with inflammatory bowel disease: results from a clinical population. Am J Gastroenterol 2001;96:1816-1821.

2. van Langenberg DR, Gibson PR. Systematic review: fatigue in inflammatory bowel disease. Aliment Pharmacol Ther 2010;32:131-143.

3. Functional Assessment of Chronic Illness Therapy-Fatigue: 1 13- 
item FACIT Fatigue Scale. FACIT Measurement System. Available from: http://www.facit.org/FACITOrg/Questionnaires [Accessed 24 July 2020].

4. Jelsness-Jørgensen LP, Bernklev T, Henriksen M, Torp R, Moum BA. Chronic fatigue is more prevalent in patients with inflammatory bowel disease than in healthy controls. Inflamm Bowel Dis 2011;17:1564-1572.

5. Romberg-Camps MJ, Bol Y, Dagnelie PC, et al. Fatigue and healthrelated quality of life in inflammatory bowel disease: results from a population-based study in the Netherlands: the IBD-South Limburg cohort. Inflamm Bowel Dis 2010;16:2137-2147.

6. Römkens TE, van Vugt-van Pinxteren MW, Nagengast FM, van Oijen MG, de Jong DJ. High prevalence of fatigue in inflammatory bowel disease: A case control study. J Crohns Colitis 2011;5:332-337.

7. Kinnucan JA, Rubin DT, Ali T. Sleep and inflammatory bowel disease: exploring the relationship between sleep disturbances and inflammation. Gastroenterol Hepatol (N Y) 2013;9:718-772.

8. Ranjbaran Z, Keefer L, Farhadi A, Stepanski E, Sedghi S, Keshavarzian A. Impact of sleep disturbances in inflammatory bowel disease. J Gastroenterol Hepatol 2007;22:1748-1753.

9. Keefer L, Stepanski EJ, Ranjbaran Z, Benson LM, Keshavarzian A. An initial report of sleep disturbance in inactive inflammatory bowel disease. J Clin Sleep Med 2006;2:409-416.

10. Graff LA, Vincent N, Walker JR, et al. A population-based study of fatigue and sleep difficulties in inflammatory bowel disease. Inflamm Bowel Dis 2011;17:1882-1889.

11. Office of Communications and Public Liaison. National Institute of Neurological Disorders and Stroke. Brain basics: understanding sleep. Available from: https://www.ninds.nih.gov/Disorders/ Patient-Caregiver-Education/Understanding-Sleep [Accessed 24 July 2020].

12. Cote, K. Canadian Sleep Society. Normal sleep: patient information brochure. Available from: https://css-scs.ca/resources/brochures/ normal-sleep [Accessed 24 July 2020].

13. Ohayon MM, Carskadon MA, Guilleminault C, Vitiello MV. Metaanalysis of quantitative sleep parameters from childhood to old age in healthy individuals: developing normative sleep values across the human lifespan. Sleep 2004;27:1255-1273.

14. Kishi A, Natelson BH, Togo F, Struzik ZR, Rapoport DM, Yamamoto Y. Sleep-stage dynamics in patients with chronic fatigue syndrome with or without fibromyalgia. Sleep 2011;34:1551-1560.

15. Tinsley A, Macklin EA, Korzenik JR, Sands BE. Validation of the functional assessment of chronic illness therapy-fatigue (FACIT-F) in patients with inflammatory bowel disease. Aliment Pharmacol Ther 2011;34:1328-1336.

16. Buysse DJ, Reynolds CF 3rd, Monk TH, Berman SR, Kupfer DJ. The
Pittsburgh Sleep Quality Index: a new instrument for psychiatric practice and research. Psychiatry Res 1989;28:193-213.

17. Beck AT, Guth D, Steer RA, Ball R. Screening for major depression disorders in medical inpatients with the beck depression inventory for primary care. Behav Res Ther 1997;35:785-791.

18. Cella D, Lai JS, Chang CH, Peterman A, Slavin M. Fatigue in cancer patients compared with fatigue in the general United States population. Cancer 2002;94:528-538.

19. Okubo N, Matsuzaka M, Takahashi I, et al; Hirosaki University Graduate School of Medicine. Relationship between self-reported sleep quality and metabolic syndrome in general population. $B M C$ Public Health 2014;14:562.

20. Hunt M, Auriemma J, Cashaw AC. Self-report bias and underreporting of depression on the BDI-II. J Pers Assess 2003;80:26-30.

21. Marinelli C, Savarino EV, Marsilio I, et al. Sleep disturbance in inflammatory bowel disease: prevalence and risk factors - a crosssectional study. Sci Rep 2020;10:507.

22. Walsleben JA, Kapur VK, Newman AB, et al. Sleep and reported daytime sleepiness in normal subjects: the Sleep Heart Health Study. Sleep 2004;27:293-298.

23. Dijk DJ. Regulation and functional correlates of slow wave sleep. $J$ Clin Sleep Med 2009;5(2 Suppl):S6-S15.

24. Bar-Gil Shitrit A, Chen-Shuali C, Adar T, et al. Sleep disturbances can be prospectively observed in patients with an inactive inflammatory bowel disease. Dig Dis Sci 2018;63:2992-2997.

25. Boselli M, Parrino L, Smerieri A, et al. Effect of age on EEG arousals in normal sleep. Sleep 1998;21:351-357.

26. Shrivastava D, Jung S, Saadat M, Sirohi R, Crewson K. How to interpret the results of a sleep study. J Community Hosp Intern Med Perspect 2014;4:24983.

27. Yue HJ, Bardwell W, Ancoli-Israel S, Loredo JS, Dimsdale JE. Arousal frequency is associated with increased fatigue in obstructive sleep apnea. Sleep Breath 2009;13:331-339.

28. Epstein LJ, Kristo D, Strollo PJ Jr, et al; Adult Obstructive Sleep Apnea Task Force of the American Academy of Sleep Medicine. Clinical guideline for the evaluation, management and longterm care of obstructive sleep apnea in adults. J Clin Sleep Med 2009;5:263-276.

29. Kunz D, Bes F. Exogenous melatonin in periodic limb movement disorder: an open clinical trial and a hypothesis. Sleep 2001;24:183-187.

30. Chesson AL, Wise M, Davila D, et al; Standards of Practice Committee of the American Academy of Sleep Medicine. Practice parameters for the treatment of restless legs syndrome and periodic limb movement disorder. An American Academy of Sleep Medicine Report. Sleep 1999;22:961-968. 